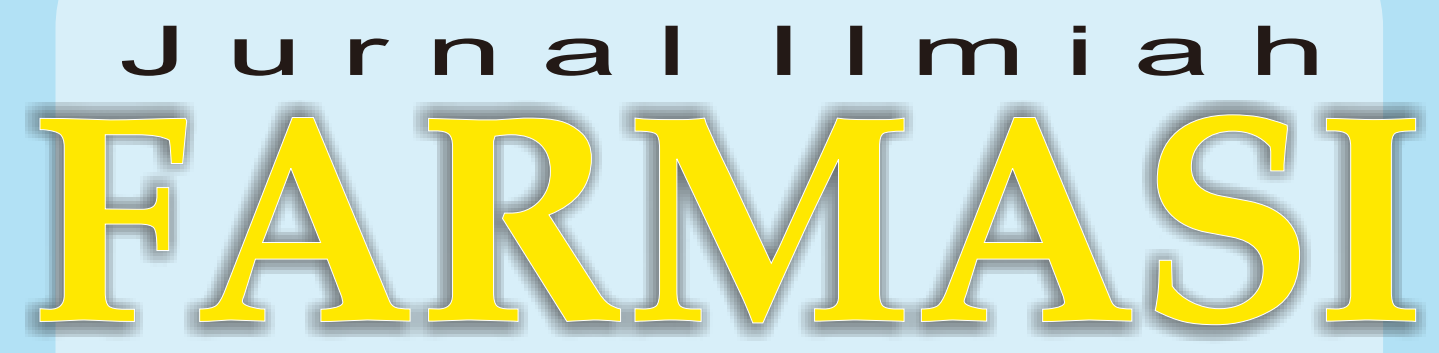

(Scientific Journal of Pharmacy) 
JURNAL ILMIAH FARMASI

(SCIENTIFIC JOURNAL OF PHARMACY)

PIMPINAN UMUM/ PENANGGUNG JAWAB

Dekan Fakultas Matematika dan Ilmu Pengetahuan Alam

Universitas Islam Indonesia

WAKIL PIMPINAN UMUM/ WAKIL PENANGGUNG JAWAB

Ketua Jurusan Farmasi FMIPA UII

\section{MITRA BESTARI}

1. Prof. Dr. Wiryatun Lestariana, Apt

2. Prof. Dr. Zullies Ikawati, Apt

3. Prof. Dr. Sudibyo Martono, Apt

4. Dr. Tedjo Yuwono, Apt

5. Prof. Dr. Dachriyanus, Apt

6. Prof. dr. Iwan Dwiprahasto, MMedSc, PhD

7. Prof. Dr. Lukman Hakim M.Sc., Apt

8. Prof. Dr. Achmad Fudholi, DEA, Apt

9. Prof. Dr. Ibnu Gholib Gandjar, DEA., Apt

\begin{tabular}{ll} 
& \multicolumn{1}{c}{ DEWAN EDITOR } \\
Ketua & : Saepudin, M.Si., Apt \\
Sekretaris & : Rochmy Istikharah, M.Sc., Apt. \\
Anggota & : Vitarani Dwi Ananda Ningrum, M.Si., Apt \\
& Okti R. Mafruhah, MSc., Apt \\
& Dimas Adhi Pradana, MSc., Apt. \\
& Fithria DA. Suryanegara, MSc., Apt. \\
& Ari Wibowo, S.Farm., Apt \\
& Arba Pramudita Ramadani, MSc., Apt. \\
& Oktavia Indrati, S.Farm., Apt.
\end{tabular}

Penerbit

Jurusan Farmasi Fakultas Matematika dan IImu Pengetahuan Alam Universitas Islam Indonesia

Alamat Penerbit Jurusan Farmasi FMIPA UII

Jl. Kaliurang Km. 14,4 Yogyakarta 55584

Telp. (0274) 896439 ext. 3047

Email: jif@uii.ac.id 


\title{
POTENSI KEJADIAN INTERAKSI OBAT PADA PENGGUNAAN OBAT UNTUK PASIEN ANAK YANG DIRAWAT INAP DENGAN DIAGNOSA INFEKSI SALURAN PERNAFASAN DI SALAH SATU RUMAH SAKIT SWASTA DI SURAKARTA
}

\author{
Saepudin, Suci Hanifah, Wachidah Rahmawati \\ Program Studi Farmasi Universitas Islam Indonesia
}

\begin{abstract}
This research was aimed at knowing potential drug interactions on drug prescribing for treatment of hospitalized pediatric patients with respiratory tract infection. Research was carried out at a private hospital in Surakarta and data were collected from medical records of patients were hospitalized during January - December 2005. Potential drug interactions were determined theoretically using some literatures on drug interaction. From total 186 patients included in this research, $67.2 \%$ were $0-4$ years old with common cold was the most diagnosed. There were $52.7 \%$ patients receiving 4-6 item of drugs and $76.9 \%$ patients were hospitalized during 1-3 days. Potential drug interactions were identified in $30.7 \%$ patients with $1.8 \%$ and $15.8 \%$ of them at level 1 and 2 clinical significance, respectively. Statistically, there was a relationship between potential drug interactions and length of hospitalization $(p=0.001)$. Some further investigations (prospectively) are needed to ensure results from this research.
\end{abstract}

Key words : drug interaction, respiratory tract infection, pediatric 